\title{
CFD Study and Investigation of the Critical Ratio for Pressure-Head Ratio inside Drainage Manholes
}

\author{
Sifa Yohana Baseka ${ }^{1}$, and Verdiana Grace Masanja ${ }^{2}$ \\ Research Scholar ${ }^{1}$, Professor $^{2}$ \\ ${ }^{1,2}$ The School of Computational and Communication Science and Engineering \\ The Nelson Mandela AfricanInstitution of Science and Technology \\ P.O. BOX 447, Arusha, Tanzania
}

\begin{abstract}
The objective of this research is to study the pressure-head rising inside manhole in pipelines, in relationship with the ratio from manhole diameters to its pipes diameters. The research team adopted CFD to simulate the manhole flows, at different conditions of varying inlet and outlet pipes diameter and manhole diameters. The risk of manhole overflow can also be reduced by controlling how fast is the rate of pressure-head rise per given flow rate. To reduce the peak and rate of rising of pressure-head column inside the manhole to be attained, the ratio between manhole widths (diameter) to its pipe diameter should be taken into considerations. Based on CFD analysis it is found that, ratios less than 3 are shown to have better results, producing lower peak values of pressure-head to be attained inside manholes.
\end{abstract}

Keywords: Manhole to Pipe Ratio, Sewage Water, Manhole Overflow.

\section{INTRODUCTION}

Sewer systems are designed to take household wastewater from toilets, bathrooms, showers, and kitchen sinks as well as wastewater from industrial and commercial buildings. These systems can be overloaded due to insufficient capacity to hold the huge residence or the inflow of storm water to the systems, which is seasonally happening on heavy rainfall. The overloading can be the cause of leakage through broken parts, as well as overflow in manholes and treatment plants [1]. In our country, the capacity of sewer systems in towns and cities is insufficient to the existing population of residence and industrialization [2]. Cities are still encountering spillage of sewage or wastewater on streets and homes massively during rainfall, which put human properties, environment sanitary and health of people at risk.

People residences, commercial areas like markets, institutional areas and industrial areas, are the main producers of urban wastewater. Wastewater leakage in cities and other towns is a threat to human health as well as environmental sanitation. They are collected and transported through the existing urban sewer networks which are composed of detention ponds or tanks, sewer pipes, manholes, force mains, septic tanks, treatment plants, and waste disposal areas [3]. Each component of the sewer network is crucial like the treatment plants which are responsible for changing the chemical behaviour of wastewater to reduce or eliminate the health or environmental problems upon their discharge [4]. These systems are complex, as they depend on geographical distribution with a hierarchical structure.

Various studies have been undertaken in the field of sewage systems for the main purpose of ensuring that collection, transportation, and deposition of wastewater are achieved to the required level such as those done by [5] and [6]. These studies have focused on areas like the optimization of the sewer systems, improvements on the performance of treatment plants, sludge systems and the least cost design of detention tanks. Despite efforts done in solving problems related to sewer systems, still, some challenges continue to exist such as leakage of wastewater from the system [7]. 
This study is the continuation of the work done by [8] on the determination of an average uplifting force exerting to the manhole cover during overflow. On controlling the wastewater overflow of manholes in sewer systems, using CFD, this study is focusing on investing the effect of manhole width (diameter) to pipe diameter ratio on the rate of pressure head development. The pressure head behaviour is going to be observed from the inlet and outlet pipe diameter variations against the manhole width (diameter) variations.

\section{MATERIALS AND METHODS}

\subsection{Model Equations}

The problem entirely involves the simulation of the fluid flow behaviour on building up the wastewater column inside the manhole. Governing equations providing the basis for modelling fluid flow in this study are derived from conservation laws of mass, linear momentum, and energy after taking into consideration some appropriate assumptions [9]. The mass conservation law is expressed by the continuity equation, equation 1 ; with $\rho$ the fluid density and $\overrightarrow{\boldsymbol{u}}$ is the velocity vector whose components in rectangular Cartesian coordinates are $u, v$ and $w$ in the $x, y$ and $z$ directions, respectively. The first term in equation 1 is the instantaneous change of density with time in the control volume while the second term represents the rate of mass flux passing out of the control surface per unit volume. It ensures that the net inward mass flux is equal to the rate of change of mass in the computational domain. The linear momentum conservation law is expressed by the equations of motion also known as NavierStokes equations, equation 2; with $F$, the force per unit mass, pressure $p$ and $\tau$ being the viscous stress tensor. Equations of motion are the generalization of Newton's second law of motion for the conservation of linear momentum [10], by which for each control volume, the sum of forces acting is regarded to be equal to the rate of change of momentum. The conservation of energy is expressed by equation 3 , with $T$ the absolute temperature, $\varphi$ the dissipation function representing the work done against the viscous forces, $c_{p}$ the specific heat capacity at constant pressure and $\rho$ the fluid density [11]. It ensures the conservation of energy distribution on the flow.

$$
\begin{aligned}
& \frac{\partial \rho}{\partial t}+\nabla \cdot(\rho \vec{u})=0 \\
& \frac{\partial}{\partial t}(\rho \vec{u})+\nabla \cdot(\rho \vec{u} \vec{u})=-\nabla p+\nabla \cdot \tau+\rho F \\
& \rho c_{p}\left(\frac{\partial T}{\partial t}+(u . \nabla) T\right)=k \nabla^{2} T+\varphi
\end{aligned}
$$

Except for higher Mach number values of moving gas, water flows are incompressible [12]. The volume of every portion of the moving water remains unchanged throughout the time flow. Therefore, the flow of wastewater is incompressible, its rate of change of density being equal to zero. For a Newtonian fluid, the viscous stresses from its flow are linearly proportional to the velocity gradient, equation 4 , where $x$ and $y$ are indices for direction representation and $\tau_{x y}$ is shear stress acting along the $x$ direction perpendicular to $y$ the direction. Water is a Newtonian fluid, once inflow, the shear stresses are linearly dependent on their velocity gradients [13].

$$
\tau_{x y}=\mu\left(\frac{\partial u}{\partial y}+\frac{\partial v}{\partial x}\right)
$$

The storm-water flow in the sewer system is isothermal, making heat transfer at constant temperatures. There are no significant temperature variations in the fluid being flowing [14]. There is an exchange of thermal energy between the flow system in the pipe and the surrounding environment which makes the temperature remain constant within the flow.

Due to the random and rapid flow of storm water over time that happens in full pipes, the $k-\in$ turbulence model is incorporated. Reynolds's averaged Navier-Stokes Equation contains more unknowns than equations due to Reynolds stresses [15]. The kepsilon $\quad(k-\in)$ is a two-equation model making a closure to Reynolds averaged Navier-Stokes Equations for modelling turbulence stresses. It contains two transport equations, for turbulent kinetic energy $k$, equation 5 , and the rate of dissipation of turbulent kinetic energy $\in$, equation 6 . Where $P^{(k)}$ is the production rate of turbulent kinetic energy per unit mass and $C_{\in 1}, C_{\in 2}$ $\sigma_{k}, \sigma_{\in}$ are model constants. 


$$
\begin{aligned}
& \frac{\partial k}{\partial t}+u(\nabla k)=P^{(k)}-\in+\nabla \cdot\left(\frac{v_{t}}{\sigma_{k}} \nabla k\right)+v \nabla \cdot(\nabla k) \\
& \frac{\partial \epsilon}{\partial t}+u(\nabla \in)=-C_{\in 1} \frac{\epsilon}{k} P^{(k)}-C_{\in 2} \frac{\epsilon^{2}}{k}+\nabla \cdot\left(\frac{v_{t}}{\sigma_{\epsilon}} \nabla \in\right)+v \nabla \cdot(\nabla \in)
\end{aligned}
$$

The model equations for an incompressible, Newtonian and isothermal flow is given by the set of partial differential equations, equation 7 to equation 10, consisting of the continuity equation, Reynolds averaged-Navier-Stokes Equations, the transport equations for turbulent kinetic energy $k$, and the dissipation rate $\in$. The model equations will be solved numerically to produce the results for the analysis between manhole width (diameter) to its pipe diameter ratio and the pressure head values.

$$
\nabla \cdot \vec{u}=0
$$

$$
\frac{\partial \vec{u}}{\partial t}+\vec{u} \cdot(\nabla \vec{u})=-\nabla p+\nabla \cdot \tau+g
$$

$$
\begin{aligned}
& \frac{\partial k}{\partial t}+\vec{u}(\nabla k)=P^{(k)}-\in+\nabla \cdot\left(\frac{v_{t}}{\sigma_{k}} \nabla k\right)+v \nabla \cdot(\nabla k) \\
& \frac{\partial \in}{\partial t}+\vec{u}(\nabla \in)=-C_{\in 1} \frac{\epsilon}{k} P^{(k)}-C_{\in 2} \frac{\epsilon^{2}}{k}+\nabla \cdot\left(\frac{v_{t}}{\sigma_{\epsilon}} \nabla \in\right)+v \nabla \cdot(\nabla \in)
\end{aligned}
$$

\subsection{COMPUTATIONAL DOMAIN}

The geometry for the computational domain simulating storm-water overflow is the cylindrical manhole with one inlet pipe and one outlet pipe. The basic measurements for the manhole used are from the manhole multi-link experiment from Coimbra University laboratory, Portugal [16], consisting of the $1 \mathrm{~m}$ diameter manhole with $0.3 \mathrm{~m}$ diameters on the input and output pipes. From these basic manhole dimensions, variations are made on the manhole diameters, and upon the inlet and outlet pipe diameters, Figure 1, to examine how the ratio from variation arrangement affect the pressure head development.

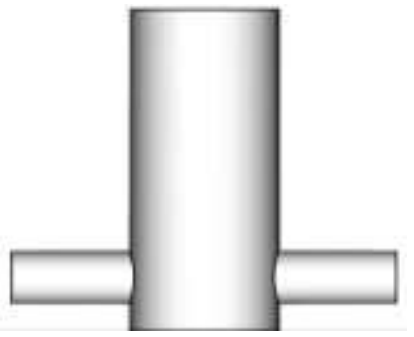

Figure 1 (a): $0.7 \mathrm{~m}$ manhole diameter, $0.3 \mathrm{~m}$ pipes diameters

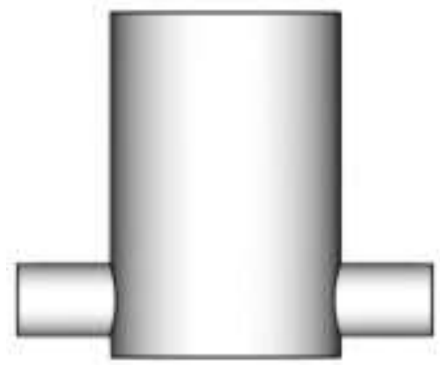

Figure 1(d): $1.0 \mathrm{~m}$ manhole diameter, $0.325 \mathrm{~m}$ pipes diameters

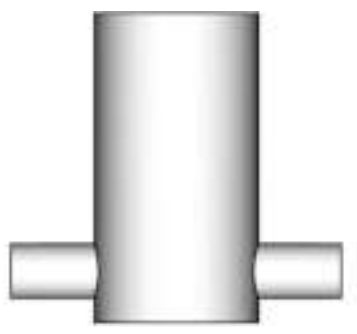

Figure1 (b): $0.8 \mathrm{~m}$ manhole diameter, Figure 1(c): $0.9 \mathrm{~m}$ manhole diameter, 0.275 m pipes diameters
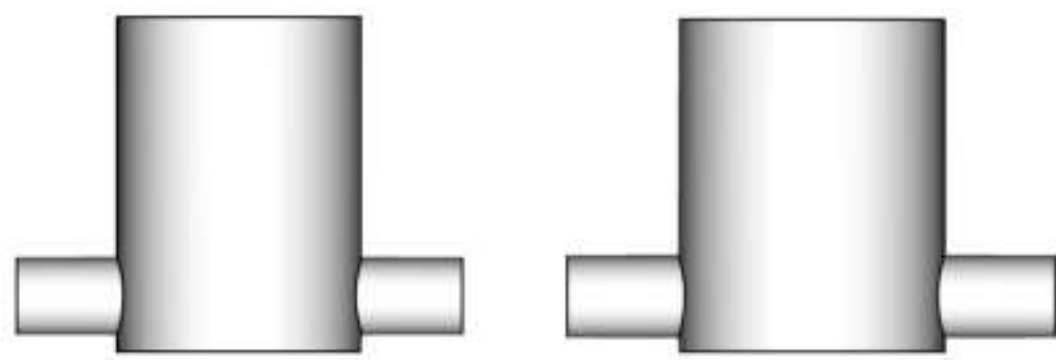

Figure 1(e): $1.1 \mathrm{~m}$ manhole diameter, Figure 1(f): $1.2 \mathrm{~m}$ manhole diameter, $0.35 \mathrm{~m}$ pipes diameters

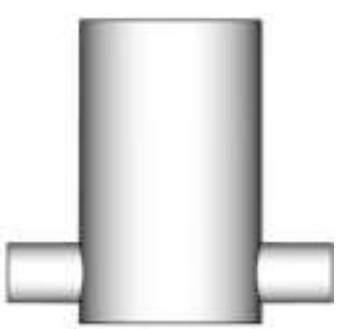

$0.3 \mathrm{~m}$ pipes diameters 


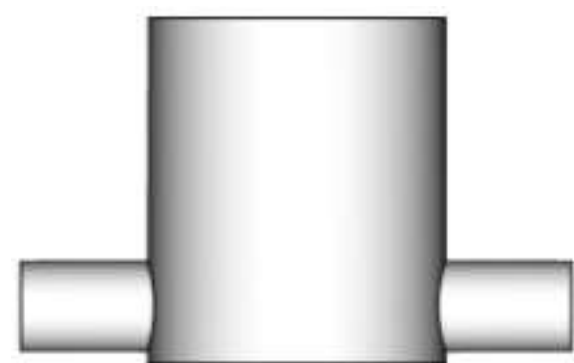

Figure 1(g): $1.3 \mathrm{~m}$ manhole diameter, $0.4 \mathrm{~m}$ pipes diameter
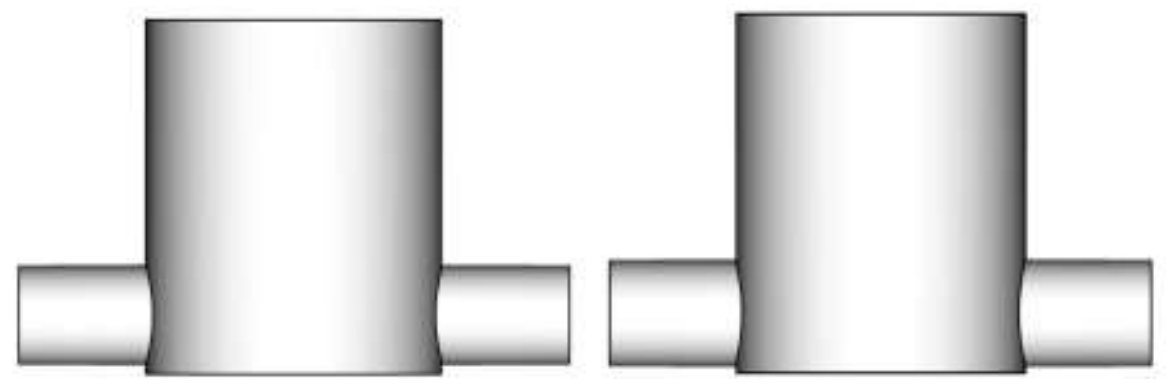

Figure 1 (h): $1.4 \mathrm{~m}$ manhole diameter, Figure 1(i): $1.5 \mathrm{~m}$ manhole diameter $0.425 \mathrm{~m}$ pipes diameters $\quad 0.45 \mathrm{~m}$ pipes diameters

The free source FreeCAD 0.19, was used to prepare the computational domain, the manhole with two pipes joined to it, the inlet pipe and the outlet pipe. The inlet pipe is the part of the pipe that carries the entering storm water to the manhole while the outlet pipe is the pipe that carries the flowing sewage which is coming out of the manhole to other parts of the sewer systems. The mesh of the geometries was done by using block Mesh and snappyhexMesh utilities in OpenFOAM 9.0. A sample of the mesh for one of the geometries is given in figure 2 .
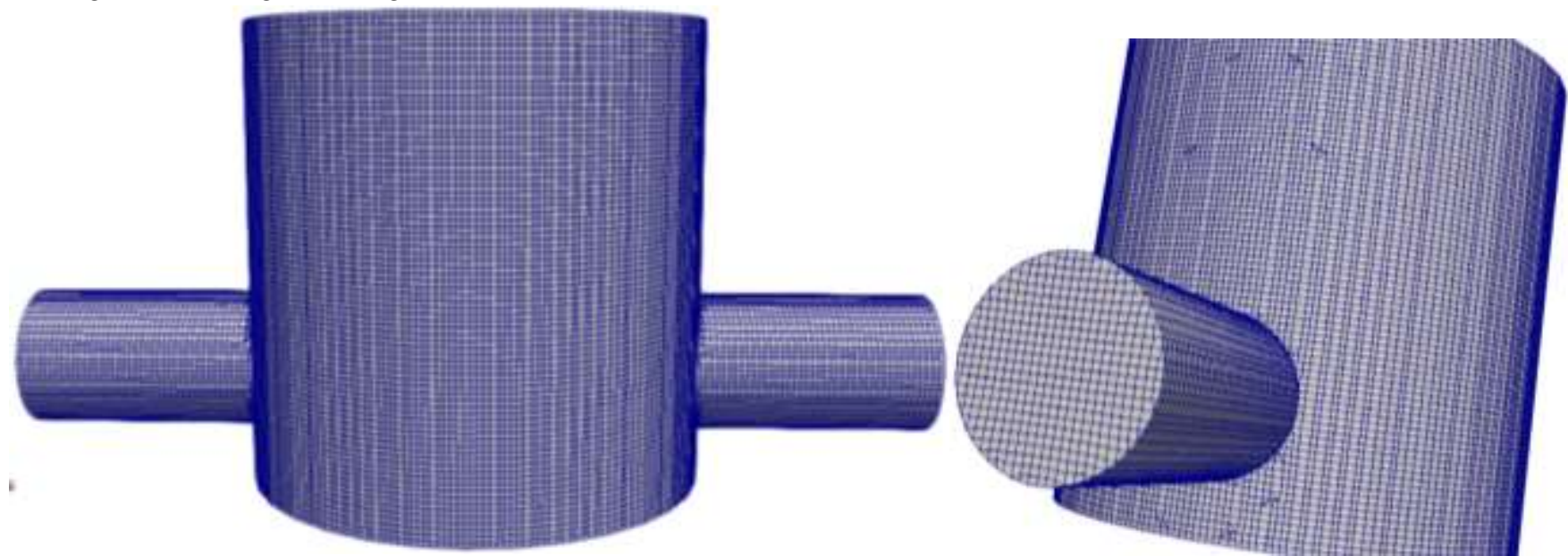

Figure 2. The sample mesh

For each geometry, there are three boundaries; the inlet, outlet, and wall. There are two kinds of outlets, one at the outlet pipe and another one at the top of the manhole. The inlet boundary is located at the patch of the inlet pipe whereas the outlet boundary is located at the patch of the outlet boundary.

\section{RESULTS AND DISCUSSION}

An investigation was made on the behaviour of water column rise inside the manhole. The rising behaviour was observed from variations of inlet and outlet pipe diameters and the variations of manhole diameter. The interval of $0.025 \mathrm{~m}$ of pipe diameters was used to study the rate of wastewater rise in the manhole. Starting from $0.25 \mathrm{~m}$, other pipe diameters that were used are $0.275 \mathrm{~m}$, $0.3 \mathrm{~m}, 0.325 \mathrm{~m}, 0.35 \mathrm{~m}, 0.375 \mathrm{~m}, 0.4 \mathrm{~m}, 0.425 \mathrm{~m}, 0.45 \mathrm{~m}$. In investigating the change in column height with a change in manhole diameter, the diameter of the manhole was changed to an interval of $0.1 \mathrm{~m}$. Different values used were $0.7 \mathrm{~m}, 0.8 \mathrm{~m}, 0.9 \mathrm{~m}, 1.0 \mathrm{~m}$, $1.1 \mathrm{~m}, 1.2 \mathrm{~m}, 1.3 \mathrm{~m}, 1.4 \mathrm{~m}$ and $1.5 \mathrm{~m}$. Figures 3 and figure 4 shows the pipe diameter variations and manhole diameter variations against the waste-water column in the manhole respectively. 

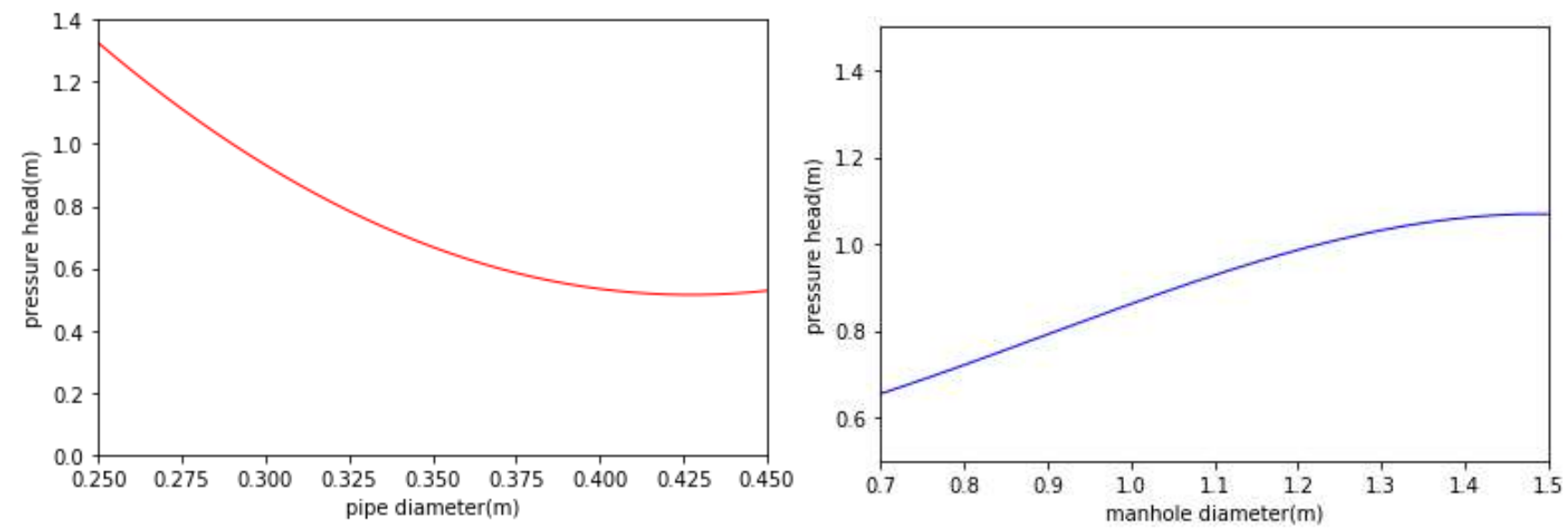

Figure 3: Pipe diameter variation with waste-water column

Figure 4: Manhole width variation with waste-water column

Figure 3 shows that at a constant inlet flow rate and manhole width, the waste-water column in the manhole decreases with increasing inlet and outlet pipe diameters connected to the manhole. That is, the larger the inlet and outlet pipe diameters are used on the manhole, the lower is the peak of the storm-water column to be attained. The smaller the pipe diameters are used in the manhole, the higher the column peak to be attained and hence larger the rate of increase storm-water column in the manhole

At constant inlet and outlet pipe diameters and inlet flow rate, the variations of manhole diameters are proportional to changes of wastewater column, Fig 4. The use of a larger manhole diameter at constant flow rates and pipes diameters corresponds to the higher peak of the column height to be attained and hence, the larger rate of rising of the waste-water column. This is because the increase of manhole diameter increases the capacity of wastewater to be reserved while the discharge rate remains relatively low. Therefore with constant inlet and outlet pipe diameter, the increase of manhole diameter makes the discharge rate becomes relatively low making the storm-water column increase rapidly. And for the decrease of manhole diameter makes the discharge rate is relatively high.

Figure 5 shows the decrease of waste-water column height with the increase in manhole diameter when pipe diameters are increased. The use of large pipe diameters on large manholes increases the discharge rate of storm water from the manhole. However, the manhole diameter to pipes diameters ratio seems significant in explaining the behaviour of the maximum peak to be attained. There is a common manhole diameter of $0.85 \mathrm{~m}$ regardless of manhole diameter variations at constant pipes diameters and variable pipes diameters, Fig 6. For diameter values less to it, the pressure-head value is always less than $0.75 \mathrm{~m}$. But for diameters larger than that, the behaviour of the change of storm-water column rise depends on the relative relationship between the manhole diameters to its pipes diameters. The relatively relationship between manhole diameter to its pipes diameter is best described using manhole diameter to its pipes diameter ratio.

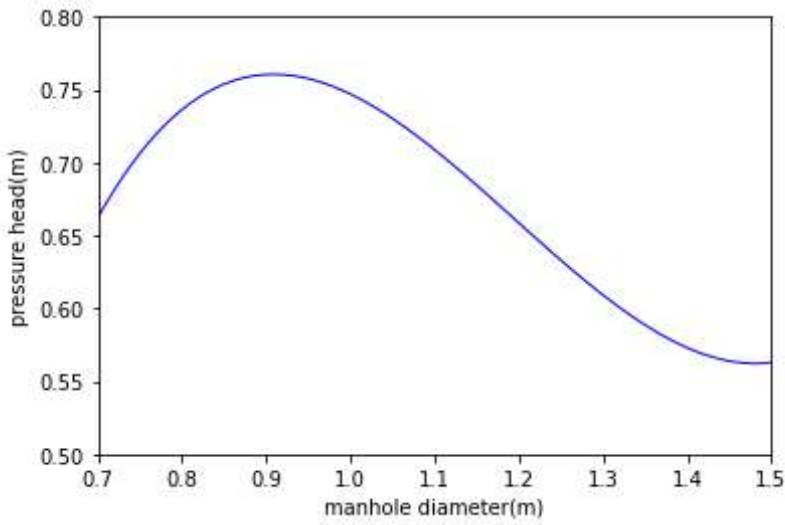

Figure 5: Manhole width variations with larger pipes

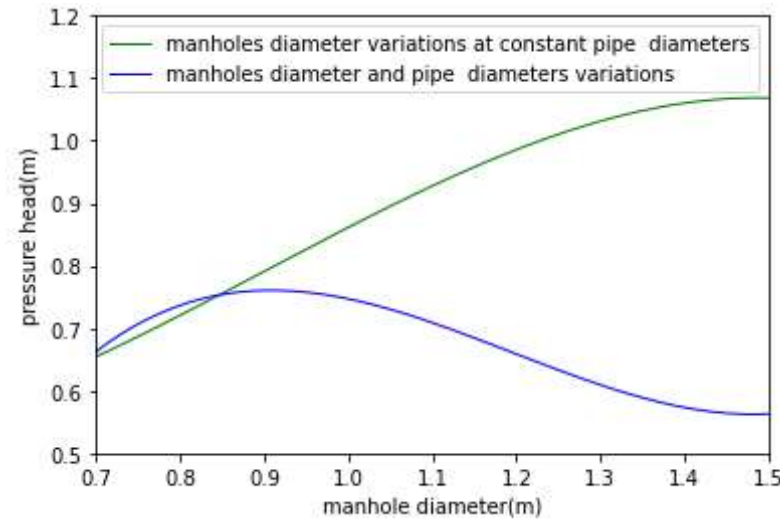

Figure. 6: Manhole at constant and variable pipe diameters

The common manhole diameter whose peak pressure head is the same regardless of the variations corresponds to the manhole diameter to pipes diameter ratio of 3 . For manhole to pipes ratios less than 3 , the column height decreases and is kept to be less than $0.75 \mathrm{~m}$ for both cases, the one with constant pipe diameters, Fig.7 and variable pipe diameters, Fig. 8. Very higher ratio values correspond to an increased peak value of the waste-water column to be attained inside the manhole as shown in Fig. 7 . 


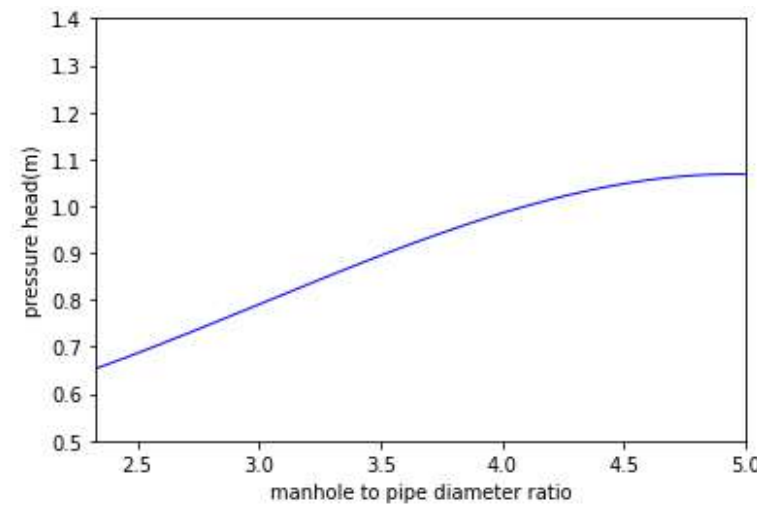

Figure. 7: Ratio at constant pipe diameters

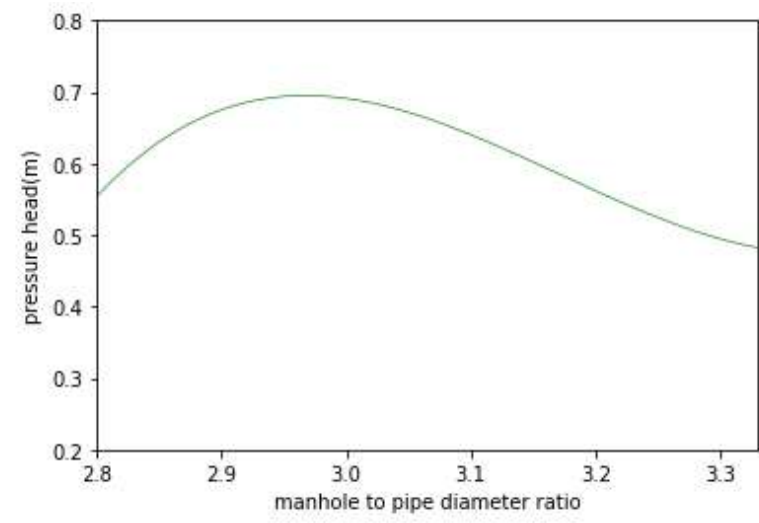

Figure.8: Ratio at variable pipe diameters

\section{CONCLUSION}

The manhole diameter and pipe diameters variations affect the rate of rising of the waste-water column inside the manhole. Larger manholes with larger pipes decrease the rate of column rise and hence the peak to be attained. The risk of manhole overflow can also be reduced by controlling how fast is the rate of waste-water column rise per given flow rate. To reduce the peak and rate of rising of waste-water column inside the manhole, the ratio between manhole widths (diameter) to its pipe diameter should be taken into considerations. Ratios less than 3 are shown to have better results of lower peak values of pressure-head inside manholes.

\section{ACKNOWLEDGEMENT}

I acknowledge the African Development Bank (AfDB) for funding, through the Nelson Mandela Africa Institution Science and Technology for work environment and facilities and study and facilities for this article.

\section{REFERENCE}

[1] T. Chang, C. Wang, A. S. Chen, and S. Djordjević, "The influence of inlet drainage in modelling flow interactions between the storm sewer system and overland surface," J. Hydrol., vol. 559, no. April 2018, pp. 541-555, 2018, doi: 10.1016/j.jhydrol.2018.01.066.

[2] M. C. Pastore, "Reworking the relation between sanitation and the city in Dar es Salaam, Tanzania," Environ. Urban., vol. 27, no. 2, pp. 473-488, 2015, doi: 10.1177/0956247815592285.

[3] R. Moeini and M. H. Afshar, "Arc Based Ant Colony Optimization Algorithm for the optimal design of gravitational sewer networks,” Ain Shams Eng. J., vol. 8, no. 2, pp. 207-223, 2017, doi: 10.1016/j.asej.2016.03.003.

[4] P. K. Swamee and A. K. Sharma, "Optimal design of a sewer line using Linear Programming," Appl. Math. Model., vol. 37, no. 6, pp. 4430-4439, 2013, doi: 10.1016/j.apm.2012.09.041.

[5] N. A. Beg, R. F. Carvalho, J. Leandro, P. Lopes, and L. Cartaxo, "Investigation of the Flow Field inside a Drainage System : Gully - Pipe - Manhole,” 2016, doi: 10.15142/T3859Z.

[6] F. Sánchez, A. S. Kaiser, A. Viedma, and A. Gómez, "Effects of the aeration on the fluid dynamic behaviour of a multizone activated sludge system," vol. 202, no. Wm, 2016, doi: 10.2495/WM160281.

[7] T. Nawrot, R. Matz, R. Błazejewski, and M. Spychala, "A case study of a small diameter gravity sewerage system in Zolkiewka Commune, Poland,” Water (Switzerland), vol. 10, no. 10, 2018, doi: 10.3390/w10101358.

[8] S. Yohana Baseka and V. Grace Masanja, "Computational Fluid Dynamics of Manhole Overflow Due to Storm-water Inflow,” J. Math. Informatics, vol. 18, no. January, pp. 33-44, 2020, doi: 10.22457/jmi.v18a3146.

[9] M. Ramakrishna, Elements of computational fluid dynamics, vol. ol. 2. 2011.

[10] A. Salih, "Conservation Equations of Fluid Dynamics,” no. February, pp. 1-8, 2011. 
[11] C. Sert, "Chapter 1 Governing Equations of Fluid Flow and Heat Transfer," ME 582 Finite Elem. Anal. Thermofluids, pp. $1-13,2012$.

[12] S. C. Xue and G. W. Barton, "Incompressible fluid flow simulations with flow rate as the sole information at synthetic inflow and outflow boundaries," Int. J. Numer. Methods Fluids, vol. 78, no. 12, pp. 739-760, 2015, doi: 10.1002/fld.4039.

[13] P. Khare, "Incompressible Flow, 4th Edition, by Ronald L. Panton,” Contemp. Phys., vol. 57, no. 1, pp. 117-118, 2015, doi: 10.1080/00107514.2015.1048302.

[14] C. Factor, I. Pressure, E. S. Menon, and S. Manual, "Thermal Hydraulics Single-phase and Multiphase Flow in Natural Gas Production Systems," 2015.

[15] I. Uddin and M. Karim, “Application of Volume Of Fluid ( VOF ) Method for Prediction of Wave Generated by Flow around Cambered Hydrofoil,” Procedia Eng., vol. 194, pp. 82-89, 2017, doi: 10.1016/j.proeng.2017.08.120.

[16] M. N. A. Beg, R. Carvalho, P. Lopes, J. Leandro, and N. Melo, "Numerical Investigation of the Flow Field inside a Manhole-Pipe Drainage System," Hydraul. Struct. Water Syst. Manag. 6th IAHR Int. Symp. Hydraul. Struct., vol. 3706281608, pp. 1-11, 2016, doi: 10.15142/T370628160853. 